\title{
Como viento, soplo o silbido: sobre las manifestaciones del muerto y la muerte en el nordeste argentino y sur del Paraguay
}

\section{César Iván Bondar}

\author{
Instituto de Estudios Sociales y Humanos, Centro Científico Tecnológico Nordeste - CONICET. Facultad de \\ Humanidades y Ciencias Sociales. Universidad Nacional de Misiones, Posadas, Misiones, Argentina. \\ (iD) https://orcid.org/oooo-0002-4686-4598 \\ Correo electrónico: cesarivanbondar@gmail.com
}

Recibido:

2 de abril de 2020

Aceptado:

13 de octubre de 2020

doi: $10.34096 /$ runa.v42i2.7716

\section{Resumen}

Proponemos como objetivo presentar y describir algunas de las modalidades de manifestación del muerto y la muerte en el nordeste argentino y el sur del Paraguay. Para ello abstraemos del corpus de la investigación las referencias sobre la presencia del muerto y la muerte en forma de viento, soplo o silbido; distinguiendo entre la muerte adulta y la muerte de los niños. Nos centramos en anunciaciones de la muerte, en el rito de los velorios y en los cementerios/ inhumaciones. Para la investigación se ha priorizado el método etnográfico aplicando entrevistas en profundidad y observaciones en diferentes contextos; el trabajo de campo se realizó entre 2010 y 2018 entre población de credo católico. Podemos dar cuenta de los sentidos diferenciales que adquieren estos movimientos del aire entre los interlocutores bajo estudio y cómo se regeneran espacios de significación y reconocimiento de parte de la memoria funeraria de los pueblos.

As the wind, breath or whistle: about the dead expressions and the death in the Argentinian Northeast and South Paraguay

\begin{abstract}
We suggest as an aim to introduce and describe some sort of expressions of the dead and the death in the Argentinian Northeast and south Paraguay. To this effect we fall back on the corpus of the investigation references about the presence of the dead and the death, shaped like wind, breath or whistle; making a difference between the death in adulthood and the death in childhood. We
\end{abstract}

\section{Palabras clave}

Aire en movimiento; Manifestaciones de la muerte; Manifestaciones del muerto; Angelito, Difunto

\section{Key words}

Moving air; The death expressions; The dead expressions; "Angelito" (Little angel); Defunct 
focus on the annunciations of death, in the visitation rituals same as cemeteries/ burials. For the investigation it has been prioritized the ethnographic method by implementing interviews in depth and observations in different contexts; the fieldwork was done between 2010 and 2018 in the Catholic creed. We can give an account on the distinct meanings this issues gain on the air between the under study speakers and about the way the significance spaces are reformed and the recognition on behalf of the peoples funeral memories.

\section{Como vento, sopro ou assobio: sobre as manifestações dos mortos e da morte no nordeste da Argentina e no sul do Para- guai}

\section{Resumo}

Palavras-chave

Ar em movimento; Manifestações da morte; Manifestações dos mortos; Anjinho; Falecido
Propomos como objetivo apresentar e descrever algumas das modalidades de manifestação dos mortos e da morte no nordeste da Argentina e no sul do Paraguai. Para isso, abstraímos do corpus da investigação as referências sobre a presença dos mortos e da morte na forma de vento, sopro ou apito; distinção entre morte de adultos e morte de crianças. Nós nos concentramos em anúncios de morte, no ritual de vigília e em cemitérios / enterros. Para a pesquisa, o método etnográfico foi priorizado aplicando entrevistas e observações em profundidade em diferentes contextos; $\mathrm{O}$ trabalho de campo foi realizado entre 2010 e 2018 entre a população de credo católico. Podemos explicar os significados diferenciais que esses movimentos do ar adquirem entre os interlocutores em estudo e como são gerados os espaços de significado e reconhecimento da memória fúnebre das pessoas.

\section{Introducción}

Anuncio de muerte: mariposa negra que vuela; perro que aúlla frente a la casa; gallo que canta solo; caída de botella de aceite; avispas negras en bandadas; abrirse una puerta por golpe de aire [...] La muerte paso cerca: cuando se siente un estremecimiento involuntario.

(González Torres, 2012, pp. 117-118)

En el presente artículo abordamos algunas de las modalidades de manifestación del muerto y la muerte en el nordeste argentino ${ }^{1}$ y sur del Paraguay. ${ }^{2}$ Seleccionamos las formas más referenciadas por los interlocutores: presencia del muerto y la muerte en forma de viento, soplo o silbido. Las manifestaciones citadas las hemos trabajado atendiendo a las diferencias que adquieren estos movimientos del aire según se trate de la muerte de adultos o de la muerte de niños. $^{3}$ de angelito y adulto recurrimos a lo señalado por Galeano Olivera (2013). El autor expone que la muerte, en la concepción folklórica, tradicional, tiene un ritual diferente según se trate de un angelito, de un angel lorus o de un adulto. El primero llega hasta los 7 años de edad, el segundo refiere a los jóvenes hasta más o menos los 20021 años, y en el tercer grupo se incluye a todos los que sobrepasan esa edad; es decir, adultos y ancianos.
Estos movimientos del aire se presentan como formas de anunciación de la muerte, o como presencia del muerto en velorios, inhumaciones y cementerios; indicarían estados, espacios y lugares de los difuntos. Si bien entre las poblaciones bajo estudio podemos localizar otras formas de presencia de la muerte y el muerto, este artículo se centra en aquellas que implican el aire en movimiento, o determinadas cualidades del aire. 
Las problemáticas se inscriben en un corpus más amplio de investigación, en el marco de los proyectos "Muerte, morir, sociedad y cultura. Nordeste Argentino y Sur de la Región Oriental del Paraguay", acreditado en la Secretaría de Investigación y Posgrado de la Facultad de Humanidades y Ciencias Sociales (FHyCS) de la Universidad Nacional de Misiones (UNaM), y “El velorio del angelito en el Nordeste Argentino y Sur de la Región Oriental de la República del Paraguay. Siglos XIX, XX y presente etnográfico", desarrollado como investigador del CONICET, inscripto en el Instituto de Estudios Sociales y Humanos. FHyCS, UNaM.

Proponemos describir y sistematizar un aspecto específico de la relación hombre-muerte-muerto desglosando la presentación en tres apartados principales. Iniciamos con una descripción general del contexto atendiendo a matrices de sentido y componentes socioculturales compartidos entre las comunidades trabajadas propiciando la comprensión de la construcción regionalizada de la muerte y la relación con los muertos; para dar cuenta de una clara distinción entre muerte adulta y muerte de niños. Asimismo, exponemos el abordaje metodológico que nos permitió el acceso al tema de interés.

Como segundo momento, presentamos las definiciones de muerte y muerto atendiendo a las consideraciones de los interlocutores.

El tercer momento comprende el abordaje de la siguiente dicotomía: movimientos del aire vinculados a la muerte de adultos y movimientos del aire vinculados a la muerte de niños. Ello nos permite hablar de variadas formas de anunciación de la muerte, presencias en forma de viento, soplo y silbido, la manifestación del muerto en el aire de los velorios, inhumaciones o cementerios (aire denso, florido, perfumado, espeso, etcétera).

El aire en movimiento referirá a la muerte adulta o del angelito, a la tranquilidad de los difuntos o a su reaparición en el mundo de los vivos, dependiendo de sus cualidades generales: si son cálidos o fríos, lúgubres o floridos, lejanos; si son silbidos o soplos. De esta forma, los movimientos del aire serán interpretados partiendo de los contextos significantes, socioculturales y de pertenencia; esta amplitud de sentidos nos ha llevado a percibir la diversidad de posibilidades que presentamos.

\section{Sobre el contexto del trabajo}

Expone Brezzo (2010) que las relaciones entre Argentina y Paraguay han marcado una estrecha vinculación durante los últimos 200 años, por un pasado común fundado en los componentes culturales, poblacionales, migratorios, acontecimientos bélicos y comercio. Maeder agrega que

la relación entre la Argentina y el Paraguay [...] se remonta a los orígenes de ambas sociedades. En dicha relación no hubo inicialmente una frontera que delimitara las jurisdicciones de las ciudades que, como Asunción y Buenos Aires, se hallaban en los extremos geográficos de aquella vasta gobernación. La delimitación entre ambas surgirá cuando las necesidades políticas y eclesiásticas requieran, para una mejor administración, dividir el distrito rioplatense y crear en ese ámbito dos provincias, separadas por límites precisos. (Maeder, 2010, pp. 7-8) 
4. La investigación no se desarrolla entre comunidades originarias guaraní-hablantes, sino entre población criolla donde el guaraní está vigente. Si bien el guaraní permanece en el nordeste argentino, se distingue con más fuerza en el Paraguay, donde la comunicación suele ser en esta lengua. En lo que refiere a las temáticas abordadas, el guaraní posee preponderancia significativa.

5. Primera etapa de demarcación: 1617-1783. Segunda etapa: 1784 y 1811. Esta última tuvo lugar en el marco del virreinato del Río de la

Plata y la creación de las intendencias de Buenos Aires y Paraguay (Maeder, 2010, p. 8).

6. Hallamos objetos bélicos en todo el espacio bajo estudio y narrativas sobre los enfrentamientos. Estas otorgan especial protagonismo a la muerte, el morir y los muertos.
Partiendo de lo señalado, listamos los hitos históricos más significativos que nos permiten ver cómo el nordeste argentino comparte con Paraguay su configuración sociohistórica.

Lo que conocemos actualmente como nordeste argentino y sur del Paraguay forma parte del gran territorio guaraní, cuya lengua perdura hasta el presente entre las comunidades con las cuales se trabaja. ${ }^{4}$

Con el advenimiento de la Orden Jesuítica en el siglo XVII, se configuraría la Paraguaria o Provincia Jesuítica del Paraguay, vigente hasta 1767. Luego de la expulsión, se suscitan nuevas demarcaciones territoriales. ${ }^{5}$ En este periodo, presenta Vara (1985), no hablamos solo del contacto entre lo católico y las creencias de comunidades prehispánicas, sino que además la religión católica de la época traía componentes animistas y múltiples creencias medievales europeas. Esta religiosidad católica se iría mezclando con lo guaraní en una construcción espiritual que se constituyó en la religiosidad rural de los siglos XVII, XVIII, XIX y XX en buena parte de la región (Bondar, 2015).

Asimismo, entre los conflictos referidos por Brezzo (2010) se puede citar la Guerra Guazú (1865-1870), que implicó directamente al territorio bajo estudio. ${ }^{6}$

De esta forma, para Brezzo (2010), otro de los vínculos bilaterales lo constituyen las relaciones internacionales (históricas y actuales), atravesadas desde hace 200 años por los exilios como consecuencias de guerras y dictaduras, y la circulación entre políticos y letrados comunes a ambos países.

Entre los interlocutores se remarca la circulación y familiaridad entre Paraguay y dos provincias argentinas en especial, Formosa y Corrientes. Esta familiaridad queda registrada en los aportes de Deniri sobre las relaciones de Corrientes con Paraguay luego de la muerte de Gaspar Rodríguez de Francia en 1840.

28 de agosto de 1841. El NC publica la ratificación del ...tratado de amistad, comercio y navegación...' con el Paraguay, que, entre otras cuestiones, establece: Amistad y recíproca libertad de comercio, Corrientes y la Villa del Pilar como terminales, Que ...los hijos de ambos estados serán considerados como naturales de uno y otro país para uso libre de sus derechos...' (Deniri, 2017, p. 83)

De esta forma, la frontera no opera solamente como delimitación, sino además como espacio de familiaridad y consolidación de relaciones. Sin olvidar las actividades económicas e intercambios históricos, vigentes y cotidianos:

esta relación [...] estuvo centrada entre el sur del Paraguay Oriental y la provincia de Corrientes, unidas por vínculos históricos, relaciones políticas e intercambios económicos. Es notorio, por otra parte, que esa relación se extendió más tarde a otros tramos de la frontera y se consolidó recientemente con obras de infraestructura y modernas comunicaciones. (Maeder, 2010, p. 8)

Más allá de la delimitación geoespacial de lo que hoy conocemos como nordeste argentino y sur del Paraguay, el componente cultural continúa siendo la base sustancial de unidad y comunidad: lengua, gastronomía, danza, música, calendario litúrgico de festividades y prácticas votivas a los santos, alianzas familiares y parentales, etcétera. 
Como parte de este componente cultural, prestamos especial atención a cómo los vínculos con la muerte, los muertos, las situaciones de muerte y el morir se configuran como intensos, familiares y cotidianos (Bondar, 2015). Hallamos una matriz compartida en la thanatocultura o cultura funeraria.

Banducci Júnior y Romero (2011, p. 4) resaltan la relevancia de la muerte y su presencia doméstica entre las comunidades bajo estudio: "Em casa, os altares repletos de imagens de santos, também se constituem en locais para rezas constantes em favor dos vivos e dos mortos". Estos microrritos cotidianos (Finol, 2009), cuando refieren a los muertos, condensan una doble significación: ayudar al alma del recién fallecido y propiciar la unidad entre los vivos (Hertz, 1960). Juntarse a rezar por los muertos ocupa un lugar importante en el cotidiano, aún más en los aniversarios del nacimiento o muerte.

Cobran especial vigencia formas diversas de manifestación del muerto y de la muerte: viento, silbido, aire helado y soplo se experimentan no solo antes o durante la muerte, sino además en los velorios, inhumaciones y aniversarios.

Se pueden listar otras prácticas que nos permiten referir a esta complejidad entre los interlocutores: velorios, novenarios, mesa negra, luto y rezo de agonía.

López Breard (2004) señala que el velorio es un hecho muy rico en el folklore de la región, donde se pueden diferenciar varias modalidades: a) de mayores (o de muerto; ya sea a cuerpo presente o de la ropa y fotografía); b) de niños (o de angelitos y ángel loro), c) de la cruz, d) de aniversario, y e) de santos. Todos, exceptuando el de santos, se vinculan a los difuntos.

Salas (2004) expone que abundan personajes populares como rezadoras del novenario, ${ }^{7}$ lloronas ${ }^{8}$ y llamadores. ${ }^{9}$ Estos últimos coadyuvan a la purificación y elevación del alma y no se encuentran vinculados a la muerte del angelito, ya que el niño no necesita purificarse.

Para el evento del novenario se viste un altar con nueve peldaños iluminados con velas en ambos lados. A medianoche del último día, se lo "desviste"; al desnudar el altar se comparte una gran comida en la que se incluyen carne vacuna, alimentos realizados con maíz y almidón (González Torres, 2012).

En Paraguay podemos notar la vigencia del luto, luto ñemonde, ${ }^{10}$ y del ñembo'e paha. ${ }^{11}$

Estas prácticas incluyen las de preluto, como ser el rezo de agonía: implica la presencia de mujeres que rezan en el lecho de muerte por la salvación del alma del moribundo.

No debemos pasar por alto las configuraciones de las tumbas en los cementerios públicos que, según sus colores y exvotos, nos hablarán de sepulturas de niños (azules, celestes o blancas) o niñas (rosadas o blancas). Y en los adultos de afiliaciones políticas, tumbas rojas para los autonomistas y celestes para los liberales.

Ocupan un lugar privilegiado las celebraciones del Día de los Santos y Ángeles (1 de noviembre) y el Día de los Fieles Difuntos (2 de noviembre), el uso de mortajas y los cíngulos, ${ }^{12}$ las vestidoras ${ }^{13}$ de finados ${ }^{14}$ y angelitos, las ánimas en pena y los aparecidos. ${ }^{15}$
7. El novenario es presidido por el ñembo'e'ýva, quien es un "especialista" en el rezo del rosario. El último día del novenario se acostumbra hacer un karu guasu, que consiste en una cena con sopa paraguaya, chipa guasu, pastel mandio, mbeju, chipa, aloha, caña, gaseosa, torta de miel, caramelos y dulces (Galeano Olivera, 2013).

8. Denominadas en Paraguay como ñembo'e ýva.

9. Referimos a ello más adelante.

10. Del guaraní, vestir luto. "Por el angelito no se guarda luto [...] Por los jóvenes se guarda medio luto y por los adultos se guarda luto cerrado. Si se trata del padre o la madre, esposo o esposa, hijo o hija el luto incluso llega a los 2 años. Si se tratare de un familiar más alejado en el grado de parentesco, el luto se extiende hasta un año. En esta materia, la tradición permanece arrinconada en las zonas rurales, en aquellas comunidades más distantes o que menos contacto tienen con las grandes ciudades" (Galeano Olivera, 2013, s.p.).

11. Del guaraní, final del novenario. Se ofrece un banquete en nombre del difunto.

12. El cíngulo, conocido además como "cordón de muerto" o “cinturón del difunto". En piola de color blanco y trenzada, es confeccionado por conocedores de las prácticas funerarias en adultos.

13. Mujeres dedicadas a la confección del ajuar mortuorio. Se diferencian según vistan a angelitos o a difuntos adultos. Los atributos de las vestidoras se adquieren por herencia oral y pasan de mujer a mujer.

14. Expresión usada para los casos de adultos fallecidos, difuntos. Deviene del participio pasivo del verbo finar, que significa morir, expirar; empleando el sufijo ado: acción o resultado de.

15. La categoría de aparecido se relaciona de forma directa con la idea de ánima en pena. Refiere a la manifestación del alma en pena en determinada localización física; en determinados lugares habrá aparecido o estarán asombrados; "Dícese del lugar, paraje, cosas, etc., donde se cree que aparecen fantasmas, ánimas o se escuchan voces, sonidos, ruidos, etc." (López Bréard, 2004, p. 31). Las categorías emic descriptas se asocian a la muerte adulta; no se aplican a la muerte de los niños. Para esta situación se reserva la denominación de angelito. 
Resaltamos aquellas distinciones que nos convocan especialmente; las anunciaciones y presencia del muerto y la muerte: las que competen a la muerte de angelitos y su diferencia con la muerte adulta en diversas modalidades del movimiento del aire.

\section{Metodología}

16. Citamos la propuesta artística denominada Celebración de las Almas. Performance compuesta por tres estampas, en la que se combinan etnografía, danzas nativas, danza teatro y musicalización popular para representar algunas dimensiones sobre la muerte y los muertos. Estampa I: El velorio del angelito; Estampa II: Ángeles Somos, el cumpleaños/aniversario del angelito; y la Estampa III: 2 de noviembre. La convivencia. La producción puede ser observada en YouTube Estampa I: https://www.youtube.com/ watch?v=9bEcexhcKJY. Estampas II y III: https://www.youtube.com/ watch?v=GUXpsk12Elo

17. Para la elaboración de este artículo se ha seleccionado un corpus reducido de entrevistas atendiendo al recorte temático abordado. Las citas de las entrevistas son señalizadas con el indicador: varón-mujer, la edad del interlocutor, fecha de realización y el lugar de residencia dentro de las comunidades con las que se traba-

ja, localidad, ciudad, etcétera.

18. Gu igu gui Akyhyje. Los Compuesteros de Carapegua: https://www.youtube.com/ watch?v=ZtrvpzzR6IY. Angelito Purahéi: https://www.youtube. com/watch?v=N6BPoL7HVW8

19. Se retoman las referencias de algunos de los velorios e inhumaciones. Se trabajan los ejemplares en los cuales se hacen presentes los tópicos relacionados con la investigación.

20. Las traducciones guaraní-español se realizan según Krivoshein de Canese y Acosta Alcaraz (2006).
Dado que se trata de un tema altamente sensible, el proceso de investigación implicó una reflexión constante en torno a los riesgos que implica la intromisión del investigador en la vida emocional de los sujetos. La naturaleza del tema a investigar requirió de un trabajo sobre las posibles resistencias por parte de los sujetos para expresar sus vivencias y creencias. Esta problemática se vio resuelta debido a que el trabajo de campo es de larga duración lo que permite la construcción de redes sociales firmes y de confianza. A eso se suman los espacios de devolución sociocomunitaria. ${ }^{16}$ En el proceso de investigación priorizamos la etnografía como enfoque, método y texto (Guber, 2001). Se instrumentaron entrevistas a interlocutores clave y observaciones con diferentes grados de participación. Dichas entrevistas y observaciones se han realizado en domicilios particulares, velorios domiciliarios, casas funerarias y cementerios.

En este artículo se exponen aspectos devenidos de intervenciones entre población de credo católico. En el marco de los proyectos referenciados, y sobre la construcción de las nociones de muerte y morir, se han efectuado más de 150 entrevistas a interlocutores que han pasado por experiencias con la muerte y los muertos o que han recibido por medio de herencia oral la transmisión de estas narrativas. ${ }^{17}$

Para la realización de las entrevistas se fijaron tópicos conversacionales y guías para la implementación de las observaciones con diversos grados de participación. Estos fueron construyéndose a la par de la complejización de las relaciones interpersonales; atendiendo a los permisos y concesiones otorgados por los interlocutores. El acceso a los velorios fue posible por la intervención de los propietarios y empleados de las casas funerarias, trabajadores de los hospitales locales, sacerdotes y responsables de cementerios y sepultureros; también se ha contado con la colaboración de compuesteros, ${ }^{18}$ cantores, maestras de rezo y vestidoras. En el periodo del trabajo de campo se observaron 45 velorios de adultos (31 en el Paraguay y 14 en el nordeste argentino) y 25 en niños (17 en el Paraguay y 8 en el nordeste argentino), y posteriores inhumaciones. ${ }^{19}$ Asimismo, se indagó en la producción de los estudios folclóricos y literatura regional.

Siguiendo los aportes de González Torres (2012), para la referencia a ciudades, pueblos o lugares se conservará la forma tradicional de escritura del guaraní. En el caso de las palabras que no identifiquen lugares, ciudades, pueblos o no sean citas textuales, se adopta la grafía establecida en el Primer Congreso de la Lengua Guaraní-Tupí (Montevideo, Uruguay, 1950), por ejemplo: escritura tradicional Poco - nueva Poko, tradicional marangatú - nueva marangatu. ${ }^{20}$

\section{La muerte y el muerto}

Abordamos las apreciaciones sobre las nociones de muerte y muerto atendiendo a las experiencias de primera mano entre las comunidades con las cuales 
se trabajó. Tomamos, como punto de partida, algunas consideraciones desde la antropología de la muerte.

Partiendo de lo expuesto por Hertz (1960, p. 27) podemos percibir como la muerte es, de forma compleja, un "evento orgánico" y "una masa compleja de creencias, emociones y actividades".

Del mismo modo, como se señala en Bondar (2015), las dimensiones singulares y sociales se cruzan y entretejen en la muerte; su relevancia social es tal, al punto que la postura malinowskiana la considera el hito de partida y origen de la religión. Por su parte, Baumann (1992) ve en el miedo y el rechazo a la muerte el origen de toda cultura.

La variedad de aproximaciones y estudios minuciosos, tanto como extensos, que hallamos en Hertz (1960), Thomas (1983, 1985, 1993, 1999), Lebrun (1971), Ariès $(1976,1992,2000)$, Morin (1999), Vovelle $(1973,1985)$, Vovelle y Bertrand (1983), Elias (1987), Barley (1995), por citar algunos clásicos, ${ }^{21}$ dan cuenta de la enorme diversidad de modos de concebir, construir, interpretar y enfrentar la muerte y el morir; y nos enseñan que "nuestras arraigadas costumbres no vienen dadas por la Naturaleza, que podríamos cambiarlas si quisiéramos y que la muerte es un filón rico en significados" (Barley, 1995, p. 12).

Por su parte, Thomas (1993) identifica a la muerte como natural, cotidiana, aleatoria y universal. Natural, pero inesperada. Cotidiana porque todos los días mueren personas, pero sigue siendo vista como lejana y ajena. Es aleatoria: no se sabe con certeza cuándo llegará o a quien, y universal, porque todos moriremos de forma irremediable e irremplazable, por ello es única.

Por otra parte Thomas (1983, p. 297) aborda la idea de muerto, y expone que "los muertos, o los que mueren, es decir las víctimas primeras de la muerte, suscitan en los sobrevivientes un juego de actitudes y comportamientos que suelen ser muy complejos"; el muerto se presenta como el sujeto afectado por la muerte. ${ }^{22}$

Estos autores habilitan a que podamos comprender cómo los procesos de muerte y el morir no son concebidos, vividos, sentidos y configurados de forma unívoca y acrónica. No solamente las formas de interpretar y comprender la muerte, sino además que las prácticas y rituales responden a las configuraciones temporales y socioculturales. Sus diferencias se montan sobre las cualidades de edad, género, posición social, sistema de creencias, etc. Estos aspectos nos permiten ver la relevancia que la muerte tiene para la vida; que la primera forma parte de una concepción general de la segunda.

Las referencias citadas con anterioridad nos permiten adherir a la afirmación de Martínez (2013, pp. 2687-2688) en lo que refiere a la muerte como proceso o proceso de la muerte

proponemos llamar proceso de la muerte al período que comienza con los eventos de anticipación del deceso [...] Esta categoría analítica permite resaltar que la muerte no se restringe a un evento biológico único, sino a una serie de sucesos y contingencias que son socialmente interpretados como relevantes. Esta idea, además, tiene la ventaja de correr el foco de atención de la variable orgánica.

Sobre la base de las recolecciones de primera mano, las nociones de muerte y muerto amplían sus definiciones. Desde las afirmaciones emic, la muerte es
21. Para ampliar se sugiere la lectura de Engelke (2019).

22. "Mediante ritos apropiados se considera que el difunto 'ingresa' al mundo de los muertos, al de los antepasados o bienaventurados" (Musitano, 2011, p. 93). 
23. Del guaraní, tocar, tanteo, palpar. Debe ser entendido como la acción de ser tocado, palpado, tanteado por la muerte.
24. Más allá de ello, se considera que el muerto posee las mismas apetencias que los vivos: comer, beber, bailar. A esta consideración responden muchos exvotos en las tumbas. 25. Del guaraní, malo. 26. Del guaraní, bueno, piadoso. claramente un proceso, pero va más allá de lo orgánico y de las prácticas, rituales o costumbres. Los interlocutores exponen que la muerte puede ser vista, sentida, percibida, olfateaba, hasta degustada (se sienten sabores amargos, dulces o agrios). La muerte posee entidad real, forma y, en muchos casos, materialidad. La muerte, por medio de su $p o k o,{ }^{23}$ transforma al individuo en muerto o difunto, y da paso a las variadas modalidades de su manifestación.

Entre los interlocutores de Paraguay y las provincias de Corrientes y Formosa (Argentina), recabamos un complejo vocabulario utilizado para no recurrir a la palabra "muerte". Se evita nombrarla ya que ello implica invocarla:

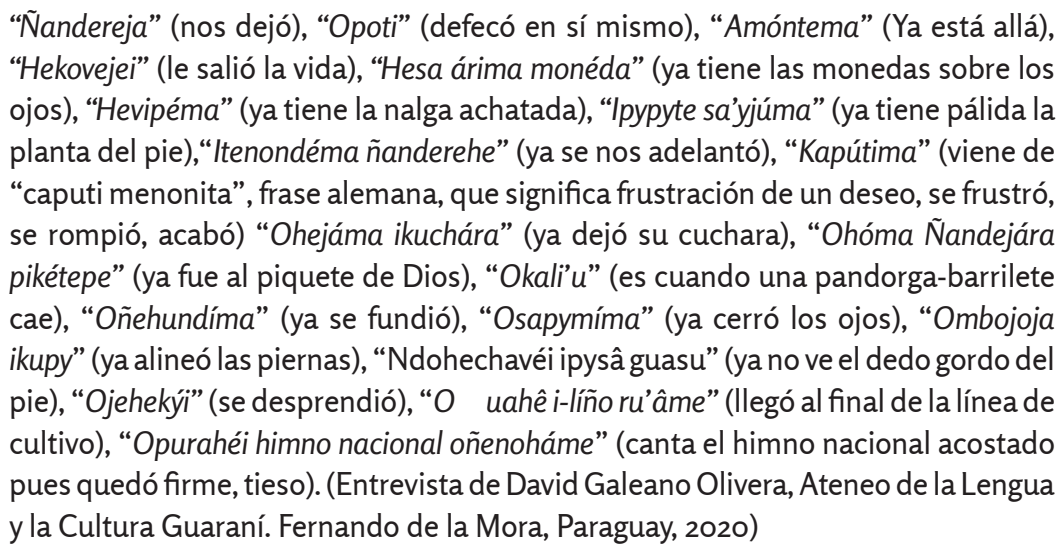

Por otro lado, el muerto, difunto o fallecido es visto como la persona afectada por la muerte, el que ya no tiene vida biofísica. ${ }^{24}$ La categoría se complejiza al incluir la clasificación de muerto $a \tilde{n} a^{25}$ y muerto marangatu. ${ }^{26}$

El muerto aña es aquel que permanece deambulando entre los vivos, algunas situaciones de este tipo las mencionamos en el apartado de los movimientos del aire en la muerte adulta. Por el contrario, el muerto marangatu no asusta y puede hacerse presente en las fechas conmemorativas del deceso o nacimiento, o ante el pedido de ayuda de algún familiar o conocido.

La categoría de muerto marangatu incluye a los angelitos; con la salvedad de que estos no son un muerto común, menos aún un finado. Esta distinción parte, principalmente, de la condición de inocencia que caracteriza a los niños. Por ejemplo, el lugar rememorativo que se les asigna a los angelitos en el calendario litúrgico oficial: son recordados el primero de noviembre, Día de los Ángeles y Santos, y no el dos de noviembre Día de los Fieles Difuntos.

Atendiendo a estas nociones emic, abstraemos algunas situaciones que nos permiten describir las modalidades de presencia y manifestación del muerto y la muerte, así como sus vínculos con los dolientes y la comunidad.

\section{Movimientos del aire en relación con la muerte de los adultos}

En lo que respecta a las situaciones de muerte en adultos, son variadas las vivencias de los interlocutores relacionadas con el aire en movimiento, principalmente en forma de viento helado, soplo frío o sensación de escalofrío. Localizamos estas situaciones en anunciaciones, velorios y cementerios. 
La anunciación de la muerte se percibe bajo la forma de silbidos por la noche, sonidos del viendo al atardecer, como viento helado, golpeteo del aire en las puertas y ventanas, o movimiento de las cortinas de la casa.

Resulta relevante destacar una clara distinción de género en lo que refiere a la anunciación de la muerte. Los interlocutores expresan que el viento frío, helado, se hace presente con más frecuencias ante la muerte de varones; no así frente a la muerte de mujeres.

La anunciación de la muerte en el caso de las mujeres se manifiesta en los golpeteos de las puertas y en los soplos entre los cortinados.

Por el contrario, los silbidos en las tardes o en las noches pueden anunciar la muerte de varones o mujeres de forma indistinta. Asimismo, el viento suele traer aromas a velas encendidas o a jazmines cuando se trata de muertes tranquilas, en muchos casos esperadas, como las provocadas por enfermedades terminales o las de ancianos.

De la misma forma, entre las comunidades con las que se trabaja, hallamos otras situaciones que ilustran esta convivencia; la presencia de determinadas aves como la lechuza, el pitogüe (benteveo) que canta en situaciones de nacimiento o muerte (que anuncia vida o muerte), el canto de las palomas, la presencia de las serpientes o algunas mariposas nocturnas. Lo relevante es que los animales e insectos voladores involucran el aire en movimiento no solo en su traslado sino además en su silbido, canto o aleteo (estos no se hallan en situaciones de muerte de niños, sino que son exclusivos en la muerte adulta).

Sobre estas modalidades de anunciación, destacamos lo expuesto por Martínez (2013, p. 2683), en relación con las experiencias en El Cajón, Catamarca, Argentina:

Hemos apuntado en otro sitio que, en términos generales, en el contexto local las lógicas clasificatorias y simbólicas suelen tomar su materia prima de la naturaleza. En particular, en relación a la muerte, ciertos animales actúan como agentes anticipatorios del deceso.

Ahora bien, en el caso de los velorios, los testimonios más recurrentes tienen que ver con la presencia del muerto en forma de viento: "se abrió la puerta y entró como un viento en el velorio" (Hombre, 39 años, Paraguay. Entrevista marzo de 2017). Esta resulta una de las situaciones más recurrentes en la narrativa de los interlocutores; las sensaciones en forma de viento asociadas no solo a la muerte sino además a la posible manifestación del alma del difunto. La presencia del alma en su propio velorio resulta frecuente en casos de la muerte adulta, y prácticamente ausente en las narrativas sobre los velorios de los niños.

Para que este viento no permanezca en el lugar del velorio, existe una práctica funeraria que habilita el tránsito al más allá, el que describimos bajo la figura del llamador. Este rol será cumplimentado por los hombres. El llamador, con tres golpes sobre el ataúd, anunciará al alma que ya ha finalizado el velorio y que debe acompañar al cuerpo a la inhumación: "se golpea el cajón, tres veces, vamos fulano, se le dice, para que no quede penando en forma de viento por ahí" (Hombre, 39 años, Paraguay. Entrevista marzo de 2017).

El golpe sobre el ataúd coadyuva a que el alma del muerto siga su camino hacia la inhumación en el cementerio y motiva su paso al más allá; en 
27. Alma en pena. Se manifiesta de diversas maneras. Deambula por los lugares que frecuentaba en vida, busca venganza o salvación.

Se expresa en forma de viento, grito, sombra. Si se establece una relación con esta, se pueden recibir recompensas, tesoros ocultos y secretos milenarios. La Pora frecuenta lugares donde "hay plata yuyguý (entierro, tesoro enterrado)" (Gonzáles Torres, 2012, p. 84).
28. Fantasma que se hace presente por la noche, puede adquirir varias formas: de mujer, oculto bajo un velo o tela transparente, colgando de los árboles o en caminos aislados. correspondencia con lo observado en la práctica de soplar tres veces sobre el rostro del angelito.

Si el alma en forma de viento permanece entre los vivos y se consolida como alma en pena, suele perturbar no solo a los dolientes sino a cualquiera que se haga presente en los lugares por donde el difunto deambula en vida. También suele percibírsela como viento helado en algunas thanatolocalizaciones especiales: árboles añejos, cruces de calles, malezales. Algunos interlocutores han expuesto experiencias directas con estas; las han percibido como un viento frío, como un soplo en la espalda, como un silbido.

Estas apariciones son reconocidas regionalmente como la Pora ${ }^{27}$ o Póra rehegua, en lengua guaraní. El encuentro con la Póra es muy complejo, el susto es tan importante que la persona se desmaya, sufre parálisis, fiebre o delirios, a veces también tartamudez; se afirma que su cabeza se llena de aire, de soplo frío. Este encuentro es descripto por Aguilera (2016, p. 26):

Cuando se manifiesta, el afectado debe retroceder siete pasos hacia atrás, sin volverse, y luego rezar un rosario de quince misterios de corrido y tres Creo en Dios Padre al revés. También se le puede dirigir la palabra y preguntarle por qué esta vagando por el mundo de los vivos, qué pide que se haga para ayudarle a alcanzar el Descanso Eterno.

La manifestación de la Pora suele estar vigente en las localizaciones donde tuvieron lugar catástrofes, guerras, enfrentamientos o riñas que culminaron en la muerte de sus participantes. Clara es la referencia mencionada por González Torres (2012) sobre los lugares donde se desenvolvieron las batallas y combates de la Guerra contra la Triple Alianza: "La gente oye o cree oír en las noches tormentosas ruidos de lucha, tronar los cañones, chocar de armas y hasta ayes y lamentos, y creen ver luces, sombras y bultos que se mueven" (González Torres, 2012, p. 84).

Otra forma de manifestación del muerto es referenciada con el nombre de malavisión. ${ }^{28}$ Resulta relevante exponer una experiencia narrada por un interlocutor de 87 años de la ciudad de Ayolas, Paraguay. Este ha compartido con nosotros su contacto con esta manifestación del muerto.

Retomamos esta experiencia ya que el interlocutor afirmaba que la malavisión se presenta flotando en el aire; se hace presente como una figura vaporosa que se disipa en el viento. Primeramente, se siente el viento helado, un grito o silbido a lo lejos, y luego se manifiesta a la vista. Estamos frente al alma del muerto y una de sus variadas formas de hacerse presente en relación con el aire en movimiento.

Continuando con las narrativas recolectadas, entre los interlocutores de Argentina y Paraguay, la manifestación del muerto adulto se asocia a un conjunto de cualidades relacionadas de forma directa con los contextos y lugares en los cuales se hace presente; atendiendo al proceso de muerte, las hemos clasificado del siguiente modo.

En los velorios, habiéndose producido la muerte, el alma del muerto puede hacerse presente en forma de viento frío que se mueve entre las piernas, un silbido a lo lejos, un soplo que mueve la cabellera del difunto o como aire escurridizo entre los arreglos de tela que penden del féretro. Asimismo, moviendo la flama de las velas de la capilla ardiente. 
En las inhumaciones y cementerios, el muerto se manifiesta en el viento entre las copas de los árboles, en el soplo que se siente en la espalda caminando entre las tumbas, en forma de viento que recorre las piernas o en el movimiento de las flamas de las velas encendidas y las flores de las ofrendas.

Otro de los puntos recurrentes en las entrevistas resulta la alusión al texto bíblico, con más frecuencia en relación con la muerte adulta. Si bien son más de veinte los versículos que hablan de la relación soplo-aliento-vida, las citas más frecuentes se basan en lo expuesto en el Génesis y el origen de la vida humana: “Entonces el Señor Dios modeló al hombre con arcilla del suelo y sopló en su nariz un aliento de vida. Así el hombre se convirtió en un ser viviente" (Santa Biblia, 1990, Gn. 2. 7, p. 6). Este soplo de vida dado por Dios, aliento dador de vida, sería devuelto al mundo de lo sagrado en forma de último suspiro en el lecho de muerte.

\section{Movimientos del aire en relación con la muerte de los niños}

En el caso de los niños, no se han registrado situaciones de anunciación de la muerte en las modalidades del aire en movimiento, sí en forma de sueños o presentimientos de parte de los interlocutores, principalmente madres, abuelas o madrinas. Consecuentemente, lo expuesto a continuación se construye sobre la base de experiencias en velorios de niños (de tipo domiciliarios), algunas situaciones de inhumaciones y prácticas rememorativas que tienen lugar durante el uno de noviembre.

En las experiencias registradas en velorios, y atendiendo al recorte temático de este artículo, cumplen un rol preponderante las figuras populares de los/ as cantores/as que, por medio de oraciones cantadas, animan a los dolientes a percibir en el niño difunto la consagración de una bendición y no la amargura o putrefacción del cadáver.

Sobre las experiencias paraguayas, exponemos el siguiente registro de Álvarez (2002, p. 106):

Cantan en el velorio un repertorio que repiten en todas las ocasiones similares. La gente baila como si fuera una fiesta popular. Camino al cementerio, con guitarras, encabezan la marcha cantando. Si hay oratorio, capilla o iglesia en las cercanías, las campanas repican de modo alegre.

La práctica protagonizada por estos personajes resulta una costumbre que, según López Breard (2004), ha ido perdiendo representatividad y vigencia. Agrega que las referencias aparecen en las narrativas funerarias de casi todos los pueblos de Latinoamérica. El cantor, llamado por el autor como decidor o recitador, recita compuestos exclusivos para la ocasión del velorio angelical. Los compuestos son

canciones improvisadas, con música apropiada al caso relatado, que se cantan con el acompañamiento de una o dos guitarras, a veces con uno o dos violines [...] Son las trovas y baladas antiguas. Hay compuestos de todos los tonos: satíricos, humorísticos, tristes, trágicos, festivos, laudatorios, etc. (González Torres, 2012, p. 50)

Agrega López Breard (2004) que la función de entonar compuestos es desempeñada, comúnmente, por mujeres, situación que hemos podido registrar en el trabajo de campo y que justifica su reseña en este apartado. 
En la siguiente cita, el interlocutor (familiar de un niño difunto) combina la relevancia del canto, el rito del velorio y el movimiento del aire en el caso de los angelitos:

Le velaron en la casa [...] estaba la que le cantaba, no había guitarra, ella cantaba se notaba con mucho sacrificio, hay gente que no aguantaba y salía para afuera. La señora quedó toda la noche cantándole a mi sobrino [...] como un soplo le salían las palabras, dulce melodía... a veces se sentía como un viento en las piernas, olor de rosas tenía, aroma dulce [...] un viento parecía que le movía el cabello al angelito. Ella decía que ese es cuando él ya está volando, como un viento era (Hombre, 35 años, Corrientes, Argentina. Entrevista noviembre de 2016)

En la narrativa, los movimientos del aire se presentan de diferente manera: en el soplo del canto, como un viento en las piernas que trae aroma dulce y a rosas, en el viento que daba movimiento a los rizos del angelito y demarcaba su ascenso al cielo, provocando sensaciones de paz y tranquilidad en el contexto del velorio.

29. En la tradición judeo-cristiana identificamos que el cosmos se organiza en niveles de creciente abstracción, sacralidad y progresiva lejanía de lo humano. Algunas versiones hablan de hasta siete niveles, pero la versión más difundida presenta tres niveles o cielos. El Primer Cielo estaría representado por lo que contiene la atmósfera (hasta donde vuelan las aves, lo observable a simple vista); el Segundo Cielo, por el Universo que contiene a la Tierra (hasta este cielo el hombre puede ambicionar experimentar). Dios ha creado estos dos cielos, pero habita en el Tercer Cielo, desde donde ha dirigido la creación. En este Tercer Cielo moran los ángeles, los seres celestiales y se goza de la visión beatífica: "San Pablo, que fue arrebatado hasta el tercer cielo, hasta los más grandes misterios de Dios y, precisamente por eso, al descender, es capaz de hacerse todo para todos" (cf. 2 Co 12, 2-4; 1 Co 9, 22). Los niños difuntos ruegan por sus dolientes desde el Tercer Cielo, junto a Dios y los demás ángeles.
La densidad del testimonio nos ubica en un umbral de extrema complejidad, ya que habla de la durabilidad del canto que se extiende por toda la noche, temporalidad requerida para la angelización del niño difunto; el soplo en forma de canto es el que lo eleva al Tercer Cielo. ${ }^{29}$ De esta forma, será la cantora la que estime si ya se ha cantado lo suficiente o el niño se encuentra muy apegado al mundo terrero y requiere más impulso para volar.

En los casos de los velorios referidos, hemos observado otra práctica que se vincula al uso del aire en movimiento. Una vez finalizado el velorio y en el momento del traslado del cuerpo a la inhumación, la cantora, madrina o abuela del angelito sopla tres veces en el rostro del niño para impulsar su llegada al Tercer Cielo; ello en caso de que la madre haya llorado mucho y en consecuencia las alas del angelito estén pesadas por cargar las lágrimas.

La presencia del angelito en forma de aire en movimiento se proyecta a otros dos espacios de memoria; en la inhumación y en las rememoraciones cuando es traído por el viento de fines de octubre:

Las flores que le tiramos cuando le llevamos al cementerio le sirven a él para volver en noviembre, el aroma queda y el viento le acerca a él este aroma, entonces él sigue el olor a flores y puede llegar bien sin perderse [...] él se fue como un viento, como un suspiro. (Mujer, 67 años, Formosa, Argentina. Entrevista noviembre, 2016)

La cita precedente refiere a un cortejo hacia el cementerio en una zona rural de la provincia de Formosa. El aroma de las flores es doblemente relevante: guía al angelito hacia su descanso eterno y señaliza el camino que deberá recorrer cada uno de noviembre para visitar a sus familiares. El enunciado "llegar bien sin perderse" habla de la complejidad de las cartografías funerarias, ya que hay "vientos de muerte" (Mujer, 67 años, Formosa, Argentina. Entrevista noviembre, 2016) que pueden desorientarlo y perturbarlo; esos vientos de muerte son muertes adultas, almas en pena, Póra, que acechan la pureza de los niños.

Con claridad, el interlocutor hace referencia a la corta vida del niño al afirmar que su presencia entre los vivos fue como un viento, como un suspiro. Aquí la idea de viento se aplica a lo efímero, a lo que pasa de forma ligera, rápida. No refiere a la presencia del muerto o la muerte; más bien es una expresión 
usada para aludir a que la vida del niño ha sido breve, que ha estado poco tiempo en el mundo de los vivos, que su estancia ha sido corta.

Si atendemos a las expresiones más comunes que asocian a los angelitos con el aire en movimiento, podemos clasificarlas según el lugar o las cualidades de la manifestación.

Los lugares de manifestación más referenciados son los velorios y cementerios. Algunas narrativas lo ubican en torno a las tumbas, jugando con los objetos que los deudos depositan allí. El alma del niño en forma de viento moviliza los juguetes de un lugar a otro.

Cuando se refiere a las cualidades de la manifestación, se citan aromas agradables, a flores, en muchos casos a rosas. También en forma de viento cálido.

El aroma a rosas se asocia a modalidades de manifestación mariana. Resulta relevante ya que los angelitos acompañan a la virgen y ocupan un lugar de resalte junto a ella. El aroma, denominado "de angelito", lo perciben principalmente las madres, abuelas o madrinas del niño difunto; llama la atención la preponderancia de lo femenino en relación con la muerte de los niños.

\section{Conclusiones}

Si bien la problemática de la muerte y el morir entre las comunidades con las que se trabaja implica la interacción de múltiples factores y particularidades, hemos recortado para esta instancia algunas de las formas que permitieron aproximarnos a experiencias específicas sobre las diversas modalidades de interacción entre el hombre, la muerte y los muertos. En esta relación, determinados aspectos del mundo ordinario y cotidiano -ligados muchas veces a la naturaleza- adquieren significación colectiva, sagrada y relativa; el aire en movimiento se constituye como algo más que un evento climático-ambiental; y significa la presencia del universo de los muertos entre los vivos.

Con claridad pudimos percibir que los muertos no utilizan el aire en movimiento; por el contrario, son ese soplo, viento, aire en movimiento o escalofrío. No se hacen presentes por medio del viento, sino que el movimiento del aire, en su diversidad, es la forma que el alma adquiere para señalizar su presencia, estadía o vigencia entre los vivos.

De esta forma podemos dar cuenta de una clara distinción cualitativa y de significación en el campo de la thanatocultura de las comunidades trabajadas: la presencia del muerto o la presencia de la muerte. Esta distinción se funda principalmente en los tiempos del proceso de muerte, cuando los interlocutores refieren a la anunciación, se ubican en el inicio del proceso de muerte: a la presencia de la muerte. En cambio, cuando aluden a etapas posteriores como velorios, cementerios, inhumaciones o rememoraciones, se centran en la presencia del alma del muerto.

En este sentido, la anunciación será territorio de la muerte, y los velorios, inhumaciones y cementerios serán territorio del muerto. Aquí habilitamos una temática a ser trabajada en otros artículos: la posibilidad de que algún familiar difunto se presente como anunciante de la muerte, pero no en forma de aire en movimiento sino materializado en figuras holográficas, psicofonías ${ }^{30} \mathrm{o}$ manifestaciones oníricas. 
31. Se entrelazan la etnografía y los procesos dialógicos para la preservación y valoración de los sentidos en torno a la muerte y los muertos. El trabajo de campo de larga duración habilitó situaciones de intercambio bajo la experiencia de los círculos "Padres con ángel", espacios de intercambio y diálogo con los padres, madres y otros familiares de los niños difuntos. A modo de grupos focales de reflexión, estos círculos se han constituido en las comunidades de Posadas (Misiones) e Isla Apipé Grande (Corrientes) -ambas en Argentina-y uno en Ayolas (Paraguay). Se dialoga sobre la muerte de los niños y se socializan las experiencias. Pudimos apreciar cómo se reelaboran los duelos y se otorga valor positivo a la memoria funeraria; lo que hemos denominado terapéutica antropológica.
Otras de las distinciones que se expone con claridad es la polaridad significante entre viento frío-helado o viento cálido, olor a muerto-muerte o aroma a flores; que corresponde a la distinción entre los adultos y los angelitos. De la misma manera, el alma de los adultos se asocia, en variadas ocasiones, a situaciones de susto, miedo o incomodidad. Por el contrario, el alma del niño ocasiona tranquilidad, armonía y protección. ${ }^{31}$

Damos cuenta de cómo el aire en movimiento, en diferentes etapas del proceso de muerte, habilita a la relación del hombre con los difuntos, habla de la continuidad de los sentidos y de la thanatocultura de las comunidades. 


\section{Q Referencias bibliográficas}

Aguilera, D. (2016). Folklore Paraguayo. Selección de Mitos, Leyendas, Fábulas y Costumbres. Paraguay: Servilibro.

" Álvarez, M. R. (2002). Lo mejor del folklore paraguayo. Paraguay: El Lector.

» Ariès, P. (1976). Essais sur l'histoire de la mort en Occident du. Moyen Age à nos jours. París: Editions du Seuil.

» Ariès, P. (1992). El hombre ante la muerte. Madrid: Taurus Humanidades.

" Ariès, P. (2000). Morir en Occidente. Desde la Edad Media hasta nuestros días. Buenos Aires: Hidalgo.

" Banducci Junior, Á. y Romero, A. (2011). Velorio da Cruz: rituais de passagem na frontera Brasil-Paraguai. Ponencia presentada a la IX Reunión de Antropología del Mercosur, Curitiba, Brasil, julio.

"Barley, N. (1995). Bailando sobre la tumba. Madrid: Taurus Humanidades.

»Brezzo, L. (2010). Las relaciones entre la Confederación y el Paraguay a comienzos del Siglo XX (1900-1930). Paraguay: El Lector.

" Baumann, Z. (1992). Mortality, Inmortality and Other Life Strategies. Oxford: Polity Press.

»Bondar. (2015). Prácticas Funerarias vinculadas a los niños difuntos (angelitos). Provincia de Corrientes y Sur de la Región oriental del Paraguay (tesis de doctorado). Programa de Posgrado en Antropología Social, Universidad Nacional de Misiones, Argentina.

»Deniri, J. E. (2017). Pedro Ferré para principiantes. Un Hombre, Un Nombre. Una época. 1824-1842. Corrientes: Ediciones Moglia.

》Elias, N. (1987). La soledad de los moribundos. Madrid: Fondo de Cultura Económica.

»Engelke, M. (2019). The anthropology of the death revisited. Annual Review of Anthropology, 48, 29-44.

» Finol, J. E. (2009). Tiempo, cotidianeidad y evento en la estructura del rito. Semiótica del Rito Venezuela: Universidad del Zulía, Universidad Católica Cecilio Acosta, Asociación Venezolana de Semiótica. En Colección de Semiótica venezolana, 6, 53-72.

» Galeano Olivera, D. (2013). La muerte en la cultura popular paraguaya. Recuperado de https://groups.google.com/forum/\#!topic/guarani-nee/xwP-UFiBZ88

"González Torres, D. (2012). Folklore del Paraguay. Paraguay: Servilibros.

》 Guber, R. (2001). La etnografía, método, campo y reflexividad. Bogotá: Norma.

» Hertz R. (1960). Death and the Right Hand. Londres: Cohen \& West.

" Krivoshein de Canese, N. y Acosta Alcaraz, F. (2006). Diccionario. Guaraní-Español. Español-Guaraní. Paraguay: Instituto Superior de Lenguas, Universidad Nacional de Asunción.

》 Lebrun, F. (1971). Les hommes et la mor en Anjou aux XVII et XVIII siecles. París: Mouton.

》 López Breard. M. R. (2004). Diccionario Folklórico Guaranítico. Corrientes: Moglia.

" Maeder, E. J. A. (2010). La frontera argentino-paraguaya. Etapas de su delimitación (1618-1950). Folia Histórica del Nordeste, 18, 7-32. 
» Martínez, B. (2013). La muerte como proceso: una perspectiva antropológica. Ciência $E$ saúde coletiva 18(9), 2681-2689.

» Morin, E. (1999). L'Homme et la Mort devant l'histoire. París: Du Seuil.

» Musitano, A. (2011). Poéticas de lo cadavérico. Teatro, plástica y videoarte de fines del siglo $X X$. Argentina: Comunicarte. Lengua y discurso.

»Salas, A. A. (2004). Creencias y espacios religiosos del NEA. Buenos Aires: Cooperativa Chilavert Artes Gráficas.

» Santa Biblia. El libro del Pueblo de Dios (Traducción argentina) (1990). El Vaticano, Roma: Librería Editrice Vaticana.

» Thomas, L.-V. (1983). Antropología de la muerte. México: Fondo de Cultura Económica.

» Thomas, L.-V. (1985). Rites de mort. Pour la paix des vivants. París: Fayard.

» Thomas, L.-V. (1993). La muerte. Barcelona: Paidós.

» Thomas, L.-V. (1999). La muerte, una lectura cultural. Barcelona: Paidós.

»Vara, A. (1985). Todo es Historia. Corrientes en el mundo guaranítico. Buenos Aires: Aleman.

» Vovelle, M. (1973). Pieté baroque et déchristianisation en Provence au XVIII siècle. Les actitudes devant la mort d'après les clauses de testaments. París: Plon. s.d.

» Vovelle, M. (1985). Ideología y mentalidades. Barcelona: Ariel.

» Vovelle, M. y Réges Bertrand (1983). La Ville des Morts. París: CNRS. 